\title{
Increased Collateral Sprouting of Primary Afferents in the Myelin- Free Spinal Cord
}

\author{
Guido Schwegler, Martin E. Schwab, and Josef P. Kapfhammer \\ Brain Research Institute, University of Zürich, CH-8029 Zürich, Switzerland
}

\begin{abstract}
After partial lesions, uninjured nerve fibers have been shown to sprout and expand their connections within the CNS of adult mammals. The extent of this anatomical plasticity in adults is rather limited in comparison to embryonic or neonatal animals. Factors that might limit sprouting of nerve fibers and suppress anatomical plasticity in the CNS include myelin-associated neurite growth inhibitory molecules present in the CNS of adult mammals. To examine further the role of these neurite growth inhibitors, we have studied the ability of primary afferent fibers to sprout in the absence of myelin within a partially deafferented spinal cord. Myelination was suppressed in the lower thoracic and lumbar spinal cord of rats using neonatal $x$-irradiation. Dorsal roots of lumbar segments L2-L4 were cut in myelinfree and normal spinal cords of 8- or 15-d-old rats. Sprouting of primary afferents was measured after $20 \mathrm{~d}$ using thiamine monophosphatase (TMP) histochemistry. TMP is a specific marker enzyme for small-diameter primary afferents that terminate in the substantia gelatinosa (lamina II) of the spinal cord. When compared to the control groups, collateral sprouting of TMP-positive afferents was significantly enhanced in the myelin-free spinal cords: in animals deafferented at postnatal day $\mathrm{P8}$, the average volume occupied by sprouting fibers in the upper dorsal horn was $0.103 \mathrm{~mm}^{3} \pm 0.008$ (mean \pm SEM) in myelin-free spinal cords and $0.044 \mathrm{~mm}^{3} \pm 0.011$ in control spinal cords. In spinal cords deafferented at P15, this difference was even larger, with $0.106 \mathrm{~mm}^{3} \pm 0.010$ in the absence of myelin and $0.031 \mathrm{~mm}^{3} \pm 0.010$ in controls. Our results indicate that myelin and its associated neurite growth inhibitors restrict collateral sprouting. These data provide further evidence that CNS myelin and its associated neurite growth inhibitors are involved in the regulation of anatomical plasticity in the normal CNS.
\end{abstract}

[Key words: collateral sprouting, substantia gelatinosa, neuronal plasticity, myelin-associated neurite growth in-

\footnotetext{
Received Aug. 1, 1994; revised Sept. 28, 1994; accepted Oct. 13, 1994.

We thank Dr. Sohail Hasan for helpful comments on the manuscript. Roland Schoeb contributed his photographic skill, and Eva Hochreutener kindly helped arrange the figures. We also thank Johanna Hoehn and Petra Aeberhard for their skillful care of the rats. We are grateful to Dr. Karina Meiri for the kind and generous gift of the $10 \mathrm{E} 8$ monoclonal antibody against GAP-43. This work was supported by grants from the Swiss National Foundation (31-29981.90), the American Paralysis Association, the International Spinal Research Trust, Regeneron Pharmaceuticals, and the International Research Institute for Paraplegia (Zürich, Switzerland).

Correspondence should be addressed to J. P. Kapfhammer, Brain Research Institute, University of Zürich, August-Forel-Strasse 1, CH-8029 Zürich, Switzerland.

Copyright 1995 Society for Neuroscience $0270-6474 / 95 / 152756-12 \$ 05.00 / 0$
}

hibitors, primary spinal cord afferents, thiamine monophosphatase]

Uninjured axons can respond to the denervation of neighboring areas by developing new fiber branches that innervate the denervated tissue. This phenomenon is referred to as "collateral sprouting" and has been reported to occur in both the PNS and CNS. In the mature CNS, particular regions have been found to show a considerable degree of collateral sprouting. These regions include the septum (Raisman and Field, 1973), the hippocampus (Cotman et al., 1981), the olfactory bulb (Devor, 1976), the cerebellum (Rossi et al., 1991), and the substantia gelatinosa of the spinal cord (Molander et al., 1988; LaMotte et al., 1989; McMahon and Kett-White, 1991). A common feature shared by all of these regions is their low degree of myelination (Kapfhammer and Schwab, 1994a). In the developing CNS, plastic fiber growth and collateral sprouting are known to be markedly enhanced (Schneider, 1973; Hulscbosch and Coggeshall, 1983a; Kaas et al., 1983; Fitzgerald, 1985). This correlates with the observation that in the developing CNS, myelin formation is still incomplete or has not yet begun. Until now, only scarce information is available about collateral sprouting in highly myelinated CNS regions such as the brainstem nuclei or the tegmentum. In the highly myelinated trigeminal nuclear complex of the rat, lesion-induced sprouting could be observed at fetal ages (Rhoades et al., 1989) but not postnatally (Renehan et al., $1989,1994)$. Taken together, these findings suggest that plastic changes requiring sprouting of nerve terminals are negatively correlated with the degree of myelination in the CNS. This correlation is particularly intriguing since myelin has been shown to contain molecules that actively inhibit nerve fiber growth (Caroni and Schwab, 1988a,b; Bandtlow et al., 1990). These neurite growth inhibitory molecules are expressed on oligodendrocyte surfaces and are contained in CNS myelin. Their distribution pattern is identical to the distribution of CNS myelin (Rubin et al., 1994). In the developing CNS, these myelin-associated neurite growth inhibitors are expressed only after cessation of longdistance fiber growth (Caroni and Schwab, 1989). After neutralization of the inhibitory activity of these molecules by the monoclonal antibody IN-1, long-distance regeneration of transected corticospinal tract fibers is markedly enhanced (Schnell and Schwab, 1990, 1993; Schnell et al., 1994). Also, sprouting of lesioned optic fibers in the superior colliculus of postnatal hamster is increased in the presence of IN-1 antibodies (Kapfhammer et al., 1992). Furthermore, in the adult rat CNS, myelin and the growth-associated protein GAP-43, a marker for fiber growth and synaptic plasticity (Skene, 1989; Benowitz and Perrone-Bizzozero, 1991; Strittmatter et al., 1992), have an inverse regional distribution in the normal adult CNS (Kapfhammer and 
Schwab, 1994a). $\Lambda$ fter suppression of myelination, G $\Lambda$ P-43 was found to be upregulated and displayed a uniformly dense distribution pattern in the rat spinal cord that is similar to that seen in neonatal animals (Kapfhammer and Schwab, 1994b). These experiments suggest that myelin and the associated neurite growth inhibitors stabilize neural connections in myelinated CNS areas and in this way may help to regulate the extent of anatomical plasticity in a given region. We have now tested this hypothesis directly by studying collateral sprouting of C-fiber primary afferents in normal and myelin-free spinal cords. We have found that collateral sprouting of primary afferents in the upper dorsal horn is significantly increased in myelin-free spinal cords.

\section{Materials and Methods}

Lesions. Male and female Lewis rats were used in this study. The animals were divided into the following groups: (1) lesioned at postnatal day P8, x-irradiated $(n=14)$; (2) lesioned at P8, not X-irradiated $(n=$ $11)$; (3) lesioned at P15, $\mathrm{X}$-irradiated $(n=12)$; (4) lesioned at P15, not $\mathrm{X}$-irradiated $(n=12)$; $(5)$ lesioned at P28, not X-irradiated $(n-8)$. P8 rat pups were anesthetized by hypothermia (Phifer and Terry, 1986), which was maintained during the surgical procedure (about $20 \mathrm{~min}$ ). Rats of $15 \mathrm{~d}$ of age or more received an intraperitoneal dose of 0.6 $\mathrm{mg} / \mathrm{kg}$ midazolam and $0.3 \mathrm{mg} / \mathrm{kg}$ Hypnorm for anesthesia. All animals were subjected to the same surgical procedure. Under aseptic conditions, a skin incision was made along the dorsal midline of the lumbar vertebral column. Using a Zeiss surgical microscope, the deep fascia and the paravertebral muscles on the right side were dissected and the intervertebral foramina of the lumbar vertebrae L2-L4 were enlarged using a small electrical drill. The ganglia and dorsal roots were visualized and the distal part of the roots as well as the ganglia were removed using a small hook. Only animals in which all three ganglia were successfully removed were processed further. The muscles and skin were carefully sutured and the animals were transferred to a heating pad until they regained consciousness. After the lesions, all animals survived for $20 \mathrm{~d}$ to allow for sprouting of the uninjured spinal cord afferents. Thus, animals lesioned at P8 were killed at P28, those lesioned at P15 were killed at P35, and those lesioned at P28 were killed at $\mathrm{P} 48$.

$X$-irradiation of spinal cord. The lower thoracic and lumbar spinal cord of rat pups were $\mathrm{X}$-irradiated at $\mathrm{P} 0$ and $\mathrm{P} 3$ in a procedure similar to that described of Savio and Schwab (1990). Briefly, rat pups were anesthetized by hypothermia. They were then placed on their side and the entire body was covered by a lead shield, leaving only the region of the lower thoracic and lumbar vertebral column exposed. The pups were then transferred to an $\mathrm{x}$-ray source, and the exposed area received a dose of $55 \mathrm{GY}$ of $50 \mathrm{kV}$ x-rays.

Tissue processing. After a survival period of $20 \mathrm{~d}$ the lesioned animals were killed by a chloral hydrate overdose $(1 \mathrm{gm} / \mathrm{kg})$ and perfused transcardially with Ringer's solution followed by $4 \%$ paraformaldehyde in $0.1 \mathrm{M}$ phosphate buffer $(\mathrm{PB})$ at $\mathrm{pH}$ 7.4. All solutions were at room temperature. After perfusion, the fixed spinal cords were inspected and only those specimens in which residues of ganglia L2-L4 were completely absent and the adjacent roots (L1 and L5) appeared undamaged were processed further. The insertion points of the dorsal roots L1, L3, and L5 were marked on the nonlesioned side using a pin covered by Orcein. The spinal cords were then dissected. After postfixation in the same fixative for $3-6 \mathrm{hr}$ at $4^{\circ} \mathrm{C}$, the spinal cords were transferred to $30 \%$ sucrose in $0.1 \mathrm{M}$ PB for cryoprotection. Thoracic and lumbar spinal cord segments were embedded in Tissue Tek and frozen by immersion in isopentane cooled to $-40^{\circ} \mathrm{C}$. Transverse sections were cut at $25 \mu \mathrm{m}$ for immunohistochemical stainings and at $50 \mu \mathrm{m}$ for thiamine monophosphatase (TMP) histochemistry on a Leitz cryostat (model 1720 Digital). Serial sections were collected at regular intervals of $350 \mu \mathrm{m}$ on Superfrost slides. Adjacent sections were collected for histological and immunohistochemical stainings.

Thiamine monophosphatase (TMP) histochemistry. For the TMP histochemical reaction, sections were rinsed in $0.2 \mathrm{M}$ tris-maleate buffer at pH 5.0, incubated in $0.25 \%$ thiamine monophosphate chloride (Sigma) and $0.08 \%$ lead nitrite in $0.04 \mathrm{~m}$ tris-maleate buffer at $\mathrm{pH} 5.0$ for 2-3 hr at $37^{\circ} \mathrm{C}$, rinsed in $0.04 \mathrm{M}$ tris-maleate buffer for $20 \mathrm{~min}$, and then developed in $0.5 \%$ aqueous ammonium sulfide (Fisher Co.) according to Knyihar and Csillik (1976). Sections were then rinsed and coverslipped with gelatin.

Immunohistochemistry and histological staining. The following antibodies were used for inmmumohistochemistry: (1) monoclonal antibody 10E8 directed against GAP-43 (Meiri et al., 1991; a kind gift of Dr Karina Meiri, State University of New York, Syracuse, NY), (2) monoclonal antibody against myelin basic protein (MBP) (Boehringer Mannheim, Germany), (3) rabbit antiserum against glial fibrillary acidic protein (GFAP) (Dakopatts, Denmark), and (4) monoclonal antibody IN-1 raised in our laboratory as previously described (Caroni and Schwab, 1988b). For staining of myelin antigens (MBP, IN-1), sections were immersed in $95 \%$ ethanol $/ 5 \%$ acetic acid for $25 \mathrm{~min}$ and then transferred

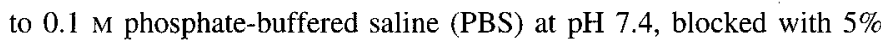
bovine serum albumin (BSA; Sigma), and incubated with the following dilutions of the antibodies: MBP, 1:500; IN-1 hybridoma supernatant, 1:5. For staining with the 10E8 antibody (GAP-43) and for GFAP, sections were rinsed in $0.1 \mathrm{M}$ PBS and then incubated with the following dilutions of the antibodies: 10E8, 1:20 containing 0.01\% digitonin (Meiri et al., 1991); GFAP, 1:5000 containing 0.1\% Triton X-100. All antibody dilutions were made in $0.1 \mathrm{M}$ PBS plus $5 \%$ BSA. Sections were incubated with the antibodies overnight at $4^{\circ} \mathrm{C}$, rinsed with PBS, incubated with a biotinylated anti-mouse or anti-rabbit antiserum (Vector, Burlingame, $\mathrm{CA}$ ), and processed for $\mathrm{ABC}$ immunohistochemistry (Vector) according to the manufacturer's instructions using $0.025 \%$ diaminobenzidine (Sigma) as a chromogen. Sections were stained with $0.125 \%$ cresyl violet to show the cellular pattern. The sections were viewed and photographed on a Zeiss Axiophot microscope.

Quantitative analysis of sprouting. Only spinal cords that fulfilled the following two criteria were processed for quantitative analysis: (1) the lesion was complete at inspection after dissection (see Tissue processing), and (2) a regular TMP labeling was seen in the upper dorsal horn on the nonlesioned control side of spinal cords. An image analysis system (Image-1) was used to quantify the area of TMP labeling on serial spinal cord sections. The area covered by TMP staining was measured on every serial section on both sides of the spinal cord. The measurements were started at a level where there was no side difference in the TMP labeling, and continued until the side difference disappeared Since the distance between the serial sections was known, the total volume of TMP-labeled area could be calculated for both sides of the spinal cord. The volume of the lesioned side was now subtracted from that of the control side to obtain the loss of TMP-positive volume on the lesioned side. To account for differences in the size of the different spinal cords and for differences in the intensity of TMP labeling from different reactions, we introduced two correction factors. First, the distance between L1 and L5 was normalized to a standard spinal cord with a distance of $2.1 \mathrm{~mm}$ per lumbar segment, and the calculated TMP volumes were corrected accordingly. Then the average area per section of TMP labeling on the control side was normalized to a standard spinal cord of $0.05 \mathrm{~mm}^{2}$ TMP-positive area per section. Again the calculated TMP volumes were corrected accordingly. By these two correction factors both variations in the size of the different spinal cords and variations of the intensity of TMP labeling were accounted for. The differences in the size of the gap of TMP labeling (loss of TMP-positive volume) on the lesioned side thus could be compared from one spinal cord to another.

To obtain direct measurements of sprouting, it would be desirable to measure the total amount of loss of TMP-positive volume immediately after the lesion. Unfortunately, in our hands, TMP activity disappeared completely following dorsal root lesions only after 7-10 d. At that time, sprouting of TMP-positive fibers might have already taken place in the deafferented area. Therefore, it was not possible to use animals with short survival times for the assessment of the total volume deafferented acutely by the lesions. We have therefore used the values from animals lesioned at P28 as the baseline to assess sprouting in the animals lesioned at younger ages. After lesions at P28, sprouting of small spinal cord afferents is known to be very limited (Hulsebosch and Coggeshall, 1983b; LaMotte et al., 1989). Therefore, the values from the animals lesioned at P28 can be regarded as a close approximation of the total deafferented volume. Since some sprouting after lesions at P28 occurs, however, the sprouting measures we calculated for animals lesioned at younger ages most likely represent a slight underestimate of the actual extent of sprouting in younger animals. 


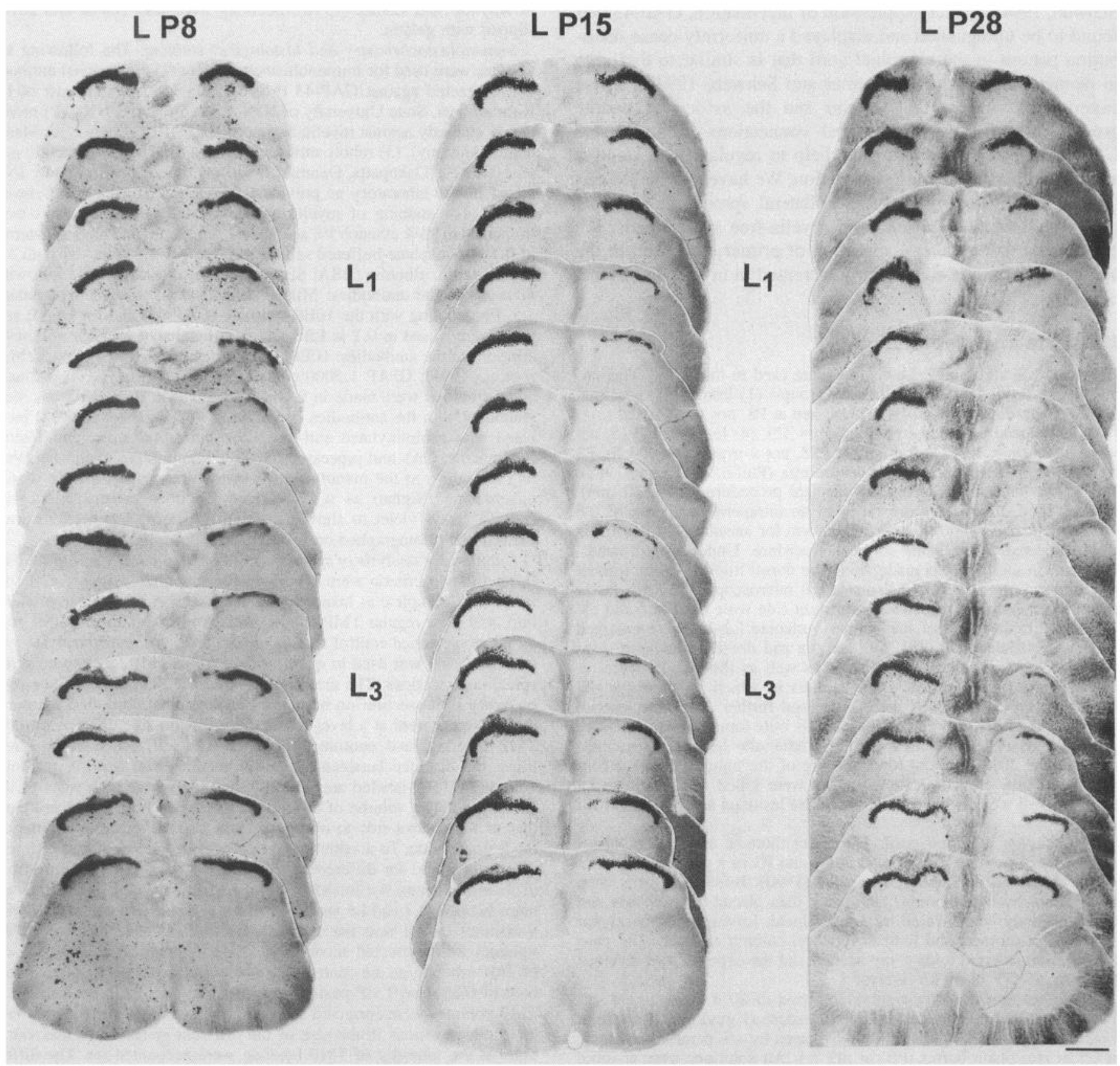

Figure 1. Age-dependent increase of volume devoid of TMP-positive fibers: serial sections of lumbar spinal cords lesioned at different time points followed by a standard survival time of $20 \mathrm{~d}$. After lesion at P8 (left column), there is a rather good recovery of TMP histochemistry on the lesioned side (indicating sprouting of TMP-positive fibers). After lesion at P15 (middle column), recovery is somewhat reduced and is less extensive after lesion at P28 (right column). The level of the entrance of the lumbar roots L1 and L3 is indicated. Scale bar, $400 \mu \mathrm{m}$.

\section{Results}

Age-dependent decrease of TMP-positive volume

We have compared the TMP-labeled areas in the substantia gelatinosa (lamina II) of normal rats lesioned at different time points. TMP is an enzyme similar to fluoride-resistant acid phosphatase (FRAP) (Knyihar-Csillik and Csillik, 1990). In the CNS, both enzymes selectively label a class of nociceptive C-fiber axons and their terminals that are found in the substantia gelatinosa (lamina II of Rexed). They have been used previously by several investigators to assess sprouting of spinal cord afferents (Fitzgerald and Vrbova, 1985; Mc Neill and Hulsebosch, 1987;
Wang et al., 1991; Reynolds and Fitzgerald, 1992). TMP histochemistry yielded very reproducible stainings and allowed a regular quantification of labelled fibers in lamina II. The volume devoid of TMP-positive fibers is the result of two opposing phenomena: initially it reflects the amount of deafferentation by the rhizotomies; after collateral sprouting has taken place, this volume will be partially filled again by TMP-positive fibers, and the original defect in TMP staining will be reduced in size.

We have first studied the effect of age on collateral sprouting of TMP-positive afferents. Figure 1 shows a comparison of lumbar spinal cords $20 \mathrm{~d}$ after lesion in animals lesioned at different 


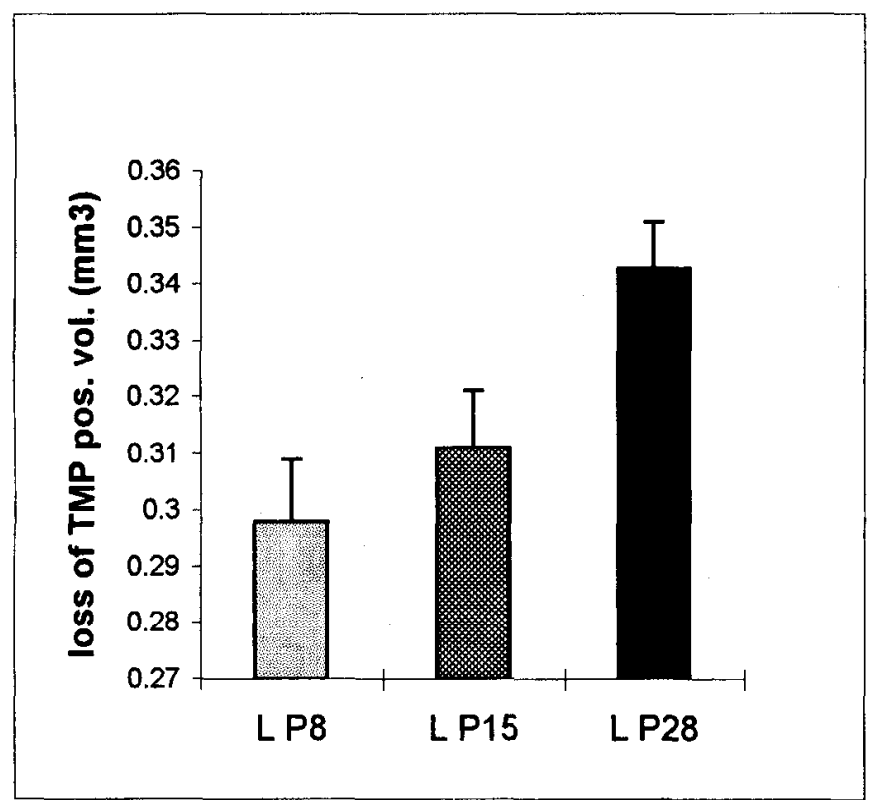

Figure 2. Quantification of age-dependent volume devoid of TMPpositive fibers: comparison of animals lesioned at P8 ( $L P 8), \mathrm{P} 15$ ( $L$ $P 15)$, and P28 ( $L P 28)$. The volume devoid of TMP-positive fibers is negatively correlated with the extent of collateral sprouting. Animals lesioned at earlier stages have a lower volume devoid of TMP-positive fibers. Values are shown as the means \pm SEM. Differences are significant for P8 and P15 when compared with P28 $(p<0.05)$, but not between P8 and P15 ( $p=0.40)$.

ages. In animals lesioned at P28, TMP activity in the upper dorsal horn almost completely disappeared between the insertion points of dorsal roots L1 and L3. This depletion of TMP-positive fibers can be considered to be an approximation of the total extent of central deafferentation created by rhizoturny of lumbar segments L2-L4 since sprouting is reported to be weak at this age (Hulsebosch and Coggeshall, 1983b; Pubols and Bowen, 1988). In spinal cords deafferented at P15, there was partial recovery of TMP activity in the degenerated area. This recovery became even more apparent in spinal cords lesioned at P8. This indicates an enhanced sprouting of the adjacent undamaged TMP-positive fiber branches from dorsal roots $\mathrm{L} 1, \mathrm{TH} 12$ and L5, L6 into the deafferented territories. No sprouting could be observed from the contralateral upper dorsal horn fibers into the denervated territory.

Quantification showed that the loss of TMP staining decreased in animals lesioned at P8 as compared to animals lesioned at P15. In animals lesioned at P28, the loss of TMP staining was maximal. The volume devoid of TMP-positive fibers decreased from $0.343 \mathrm{~mm}^{3} \pm 0.007$ (mean $\pm S E M$ ) in P28-lesioned rats to $0.311 \mathrm{~mm}^{3} \pm 0.010$ in P15-lesioned rats and to $0.299 \mathrm{~mm}^{3}$ \pm 0.011 in P8-lesioned rats (Fig. 2). Differences in the loss of TMP-positive volume between P28-lesioned and P15- or P8lesioned rats were statistically significant $(p<0.05)$. The difference between P8- and P15-lesioned rats was not significant. These results indicate an enhanced amount of sprouting in animals lesioned at P8 and P15 as compared to animals lesioned at $\mathrm{P} 28$.

\section{Effect of neonatal $x$-irradiation}

After neonatal $x$-irradiation of the lower thoracic and lumbar spinal cord, myelination was strongly suppressed in the white and gray matter. In the white matter, at P28 and, more pronounced at P35, a few myelinated fibers were present (especially in the ventral funiculi) as revealed by MBP immunostaining (Fig. 3A). Myelin-associated neurite growth inhibitors could not be detected by IN-1 immunohistochemistry (Rubin et al., 1994) throughout the entire $\mathrm{x}$-irradiated spinal cord (Fig. $3 E$ ). As previously described (Kapfhammer and Schwab, 1994b), the growth-associated protein GAP-43 was strongly upregulated in the myelin-free spinal cord throughout the white and gray matter (Fig. $3 C$ ). In contrast, the pattern of myelination and GAP-43 distribution was adult-like in normal control rats at P28 (Kapfhammer and Schwab, 1994a) (Гig. 3B,D,F). Remarkably, after neonatal $\mathrm{x}$-irradiation, the cytoarchitecture of the spinal cord remained well preserved; cresyl violet staining revealed an apparently normal cell distribution in the gray matter (Fig. 4A). Apart from a strong reduction in the size of the white matter, the laminae and their specific neuronal cell types corresponded to those in control spinal cords (Fig. 4B). GFAP staining revealed a rather normal distribution of astrocytic processes in the $\mathrm{x}$-irradiated spinal cords. In the gray matter, however, a mild gliosis was present (Fig. 4C). A remarkable finding was the expansion of the TMP-labeled area in the upper dorsal horn of $\mathrm{x}$-irradiated spinal cords. At P28, the average TMP-positive area in the dorsal horn measured on the nonlesioned side was $0.044 \mathrm{~mm}^{2} \pm 0.002$ (mean \pm SEM) in normal spinal cords, and $0.073 \mathrm{~mm}^{2} \pm 0.004$ in $\mathrm{x}$-irradiated spinal cords $(p<0.0001)$. At $\mathrm{P} 35$, the values were $0.041 \mathrm{~mm}^{2} \pm 0.001$ in normal spinal cords versus 0.066 $\mathrm{mm}^{2} \pm 0.003$ in $\mathrm{x}$-irradiated cords $(p<0.001)$. Double staining with TMP and cresyl violet revealed that this increase in size of the TMP-positive area was partly due to an invasion of lamina III by TMP-positive afferents in the myelin-free spinal cord (data not shown).

\section{Lesion-induced sprouting of primary afferents in the upper dorsal horn following neonatal $x$-irradiation}

Sprouting of TMP-positive fibers is strongly enhanced in myelin-free spinal cords. Figure 5 shows a comparison between sprouting in myelin-free and normal spinal cords following a lesion at P8. In the control spinal cord, only a small amount of TMP activity was detectable between the insertion points of dorsal roots $\mathrm{L} 1$ and L3. In contrast, in the myelin-free spinal cord, sprouting was robust and TMP-positive fibers were present throughout the whole upper dorsal horn of the lumbar spinal cord. This indicates that in the absence of myelin, TMP-positive fibers and their terminal branches sprouted over longer distances than in the normal environment. Similar results were obtained after lesions at P15, as shown in Figure 6. The difference between sprouting in normal and myelin-free spinal cords appeared to be even more pronounced than in spinal cords deafferented at P8. This phenomenon results from the fact that the extent of sprouting was the same in P8- and P15-lesioned animals in the absence of myelin, whereas in the normal spinal cord there is a tendency for sprouting to decrease in animals lesioned at older ages. This is reflected by the extended zone completely devoid of TMP-positive fibers in the upper dorsal horn of the control animals lesioned at P15.

In rats lesioned at P8, sprouting of TMP-positive fibers resulted in a volume of $0.103 \mathrm{~mm}^{3} \pm 0.008$ (mean \pm SEM) in myelin-free spinal cords $(n=14)$, but only $0.044 \mathrm{~mm}^{3} \pm 0.011$ in control spinal cords $(n b=11)$ (Fig. 6). In rats lesioned at P15, this difference was even more pronounced: $0.106 \mathrm{~mm}^{3} \pm$ 0.010 in myelin-free spinal cords $(n=12)$ and $0.031 \mathrm{~mm}^{3} \pm$ 


\section{X-RAY}
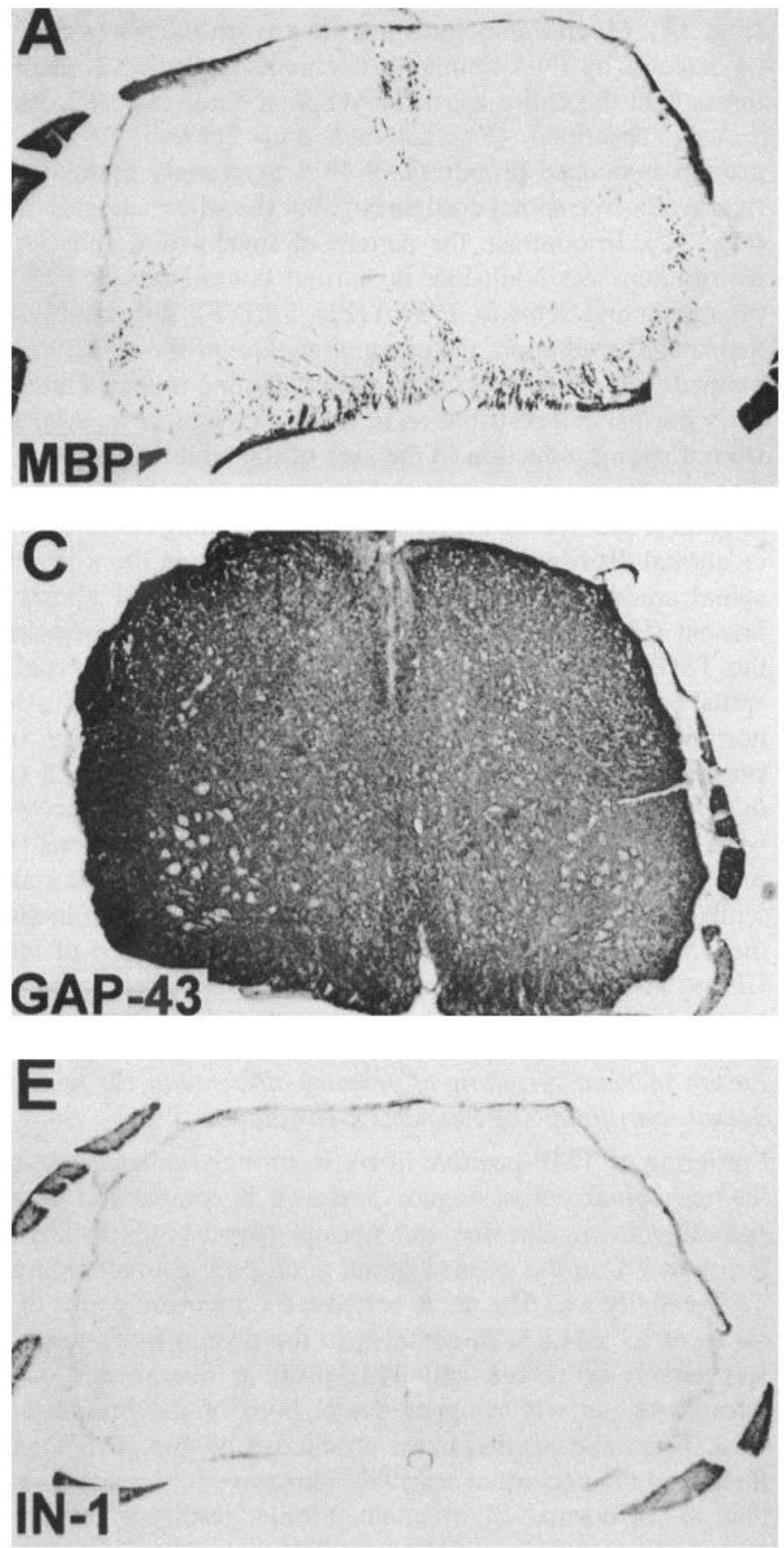

\section{CONTROL}
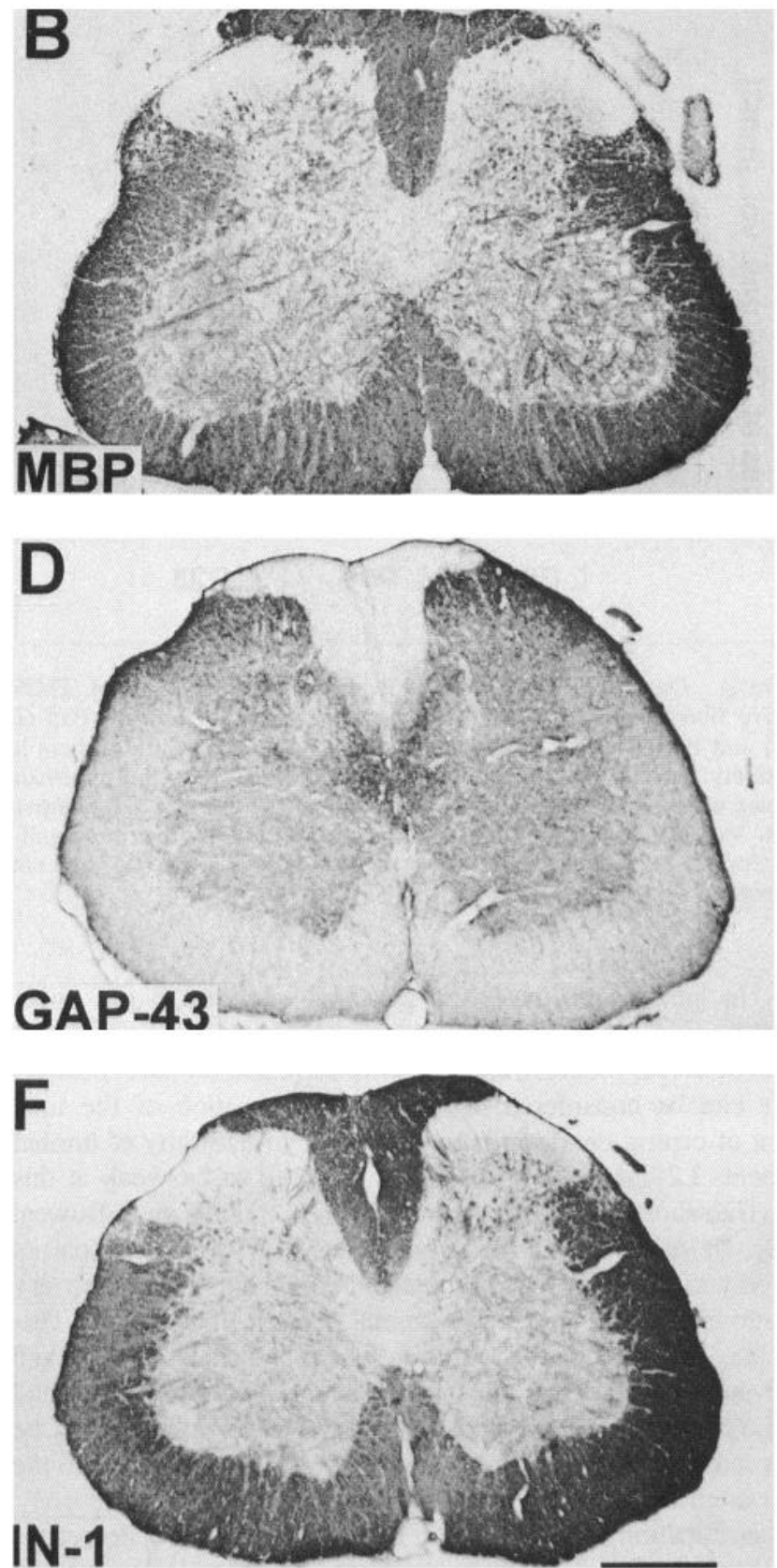

Figure 3. Suppression of myelination and upregulation of GAP-43 through neonatal $\mathrm{x}$-irradiation. Twenty-eight days after neonatal $\mathrm{x}$-irradiation, myelination is strongly suppressed in the lumbar spinal cord as judged by MBP immunohistochemistry. Only a few fibers in ventral and dorsal columns are myelinated $(A)$. GAP-43 expression is homogeneously upregulated $(C)$, whereas IN-1 antigens remain completely undetectable in the $\mathrm{x}$-irradiated spinal cord $(E)$. The control spinal cord sections show the normal adult-like distribution of MBP $(B)$, GAP-43 (D), and IN-1 (F) in $28-$ d-old rats. Scale bar, $400 \mu \mathrm{m}$.

0.010 in control spinal cords $(n=12)$ (Fig. 7). The differences between the myelin-free and control spinal cords are significant within the P8 and P15 lesioned groups with $p<0.001$.

\section{Discussion}

We have studied the effect of myelin and its associated neurite growth inhibitors on lesion-induced sprouting in the spinal cord. After lumbar rhizotomy in normal and myelin-free spinal cords, lesion-induced sprouting of primary afferent terminals was strongly enhanced in the myelin-free environment. Our results suggest that myelin and myelin-associated neurite growth inhibitors are involved in the restriction of terminal sprouting in the CNS.

TMP histochemistry as a method to assess sprouting of primary afferents in the spinal cord

We have used TMP histochemistry to assess the sprouting of C-fiber afferents in the spinal cord of rats after dorsal root le- 


\section{X-RAY}
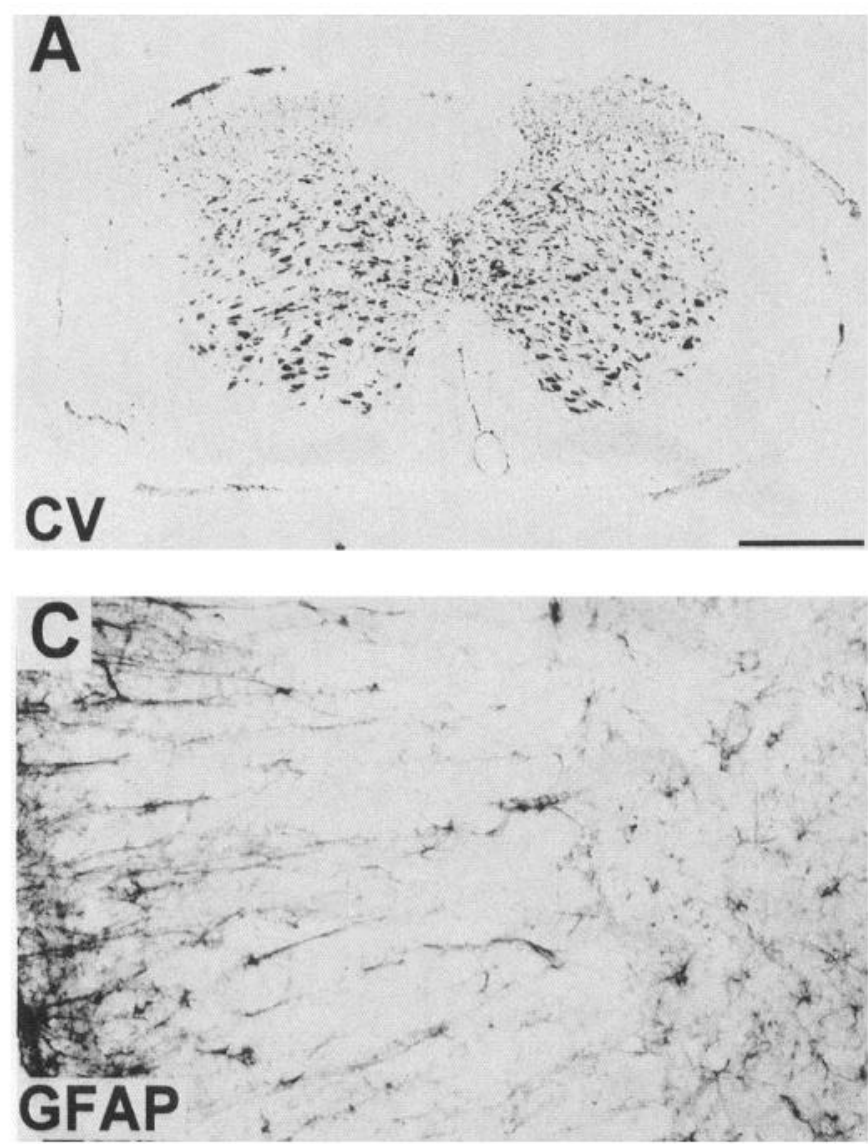

\section{CONTROL}
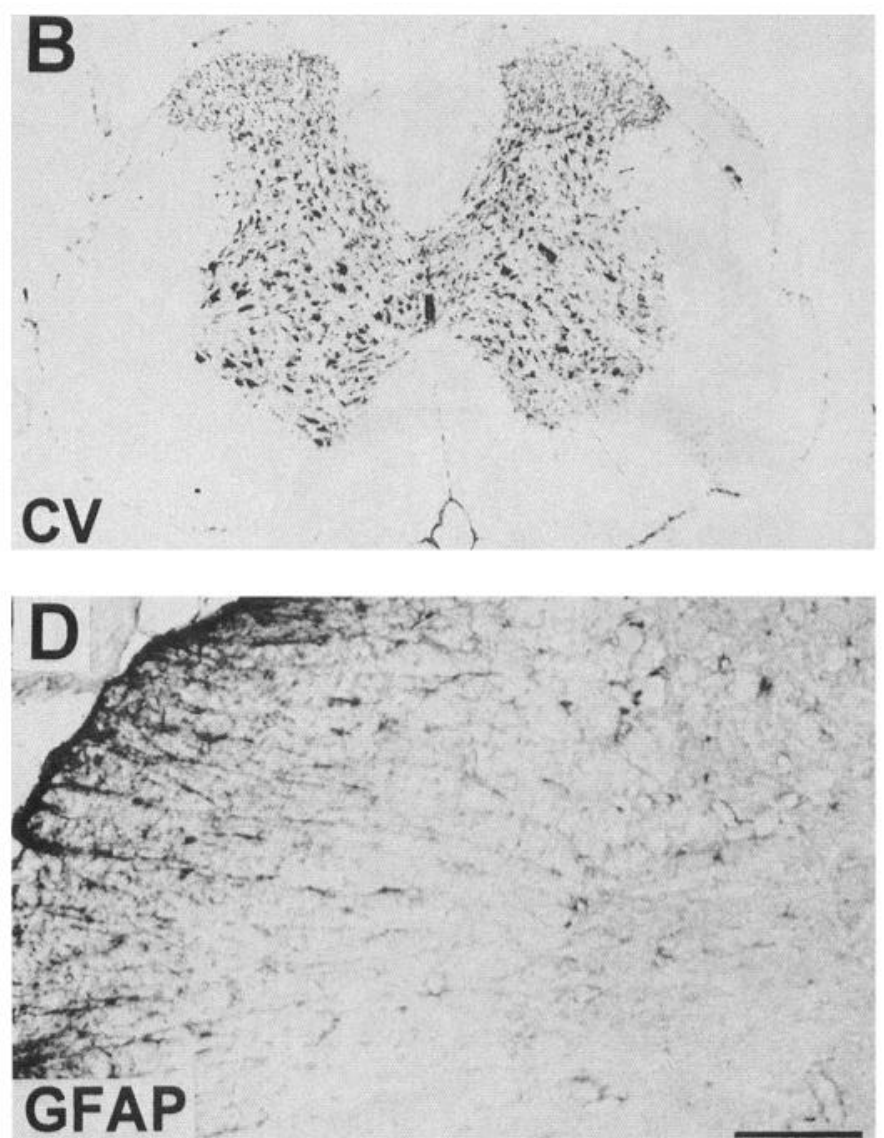

Figure 4. Cytoarchitecture of spinal cords after neonatal $\mathrm{x}$-irradiation. Apart from a strong reduction of white matter size, cytoarchitecture is well preserved in the myelin-free spinal cord as judged by cresyl violet staining $(A)$. The GFAP staining in the irradiated spinal cords shows a rather normal pattern with a mild gliosis in the gray matter $(C) . B$ and $D$ represent corresponding lumbar spinal cord sections in normal animals lesioned at the same age. Scale bars: $A$ and $B, 400 \mu \mathrm{m} ; C$ and $D, 100 \mu \mathrm{m}$.

sions. TMP is an enzyme similar to fluoride-resistant acid phosphatase (FRAP) (Knyihar-Csillik and Csillik, 1990). In the CNS, both enzymes selectively label a class of nociceptive C-fiber axons and their terminals that are found in the substantia gelatinosa (lamina II of Rexed). They have been used previously by several investigators to assess sprouting of spinal cord afferents (Fitzgerald and Vrbova, 1985; Mc Neill and Hulsebosch, 1987; Wang et al., 1991; Reynolds and Fitzgerald, 1992). Other investigators, however, have used transganglionic transport of HRP conjugates to assess sprouting. We have chosen not to use HRP tracing to analyze the sprouting of spinal cord afferents for several reasons. First, this would have required an additional step of surgery, which is particularly difficult in the case of the $\mathrm{x}$-irradiated myelin-free animals. Second, transganglionic transport of the applied tracers in our hands was quite variable from case to case. Accordingly, the number of animals analyzed by other investigators using transganglionic transport to assess sprouting is very small (Fitzgerald, 1985; Molander et al., 1988; LaMotte et al., 1989). On the other hand, with the type of lesion performed in our study, TMP histochemistry is a reliable method to assess the presence or absence of C-fiber afferents. Unlike in other studies (Fitzgerald and Vrbova, 1985; LaMotte et al., 1989; Reynolds and Fitzgerald, 1992), in our surgical procedure the dorsal root ganglia of the lesioned segments are physically removed during surgery. Since TMP activity is not present in descending projections of the spinal cord or in any other intrinsic spinal cord neurons or glial cells (Knyihar-Csillik et al., 1986), the question of an upregulation or suppression of the enzyme activity by the surgical procedure does not apply. After extensive dorsal root lesions, no enzyme activity on the lesioned side of the spinal cord can be detected over extended time periods (Wang et al., 1991). The only possible source of TMP activity in our experiments is adjacent, unlesioned dorsal root afferents. Also, general changes of TMP expression by $\mathrm{x}$-irradiation would not affect the outcome of our study because the amount of TMP labeling on the unlesioned side of the spinal cord (which in case of the myelin-free cords also was x-irradiated) was taken into account and corrected for. For these reasons, TMP labeling is a valid method to assess sprouting of a subclass of spinal cord primary afferents after dorsal root lesions.

Collateral sprouting is negatively correlated with myelination of the CNS both in the adult and during postnatal development

We have compared collateral sprouting in normal rats lesioned at P8, P15, or P28. Quantitative analysis of TMP-labeled affer- 


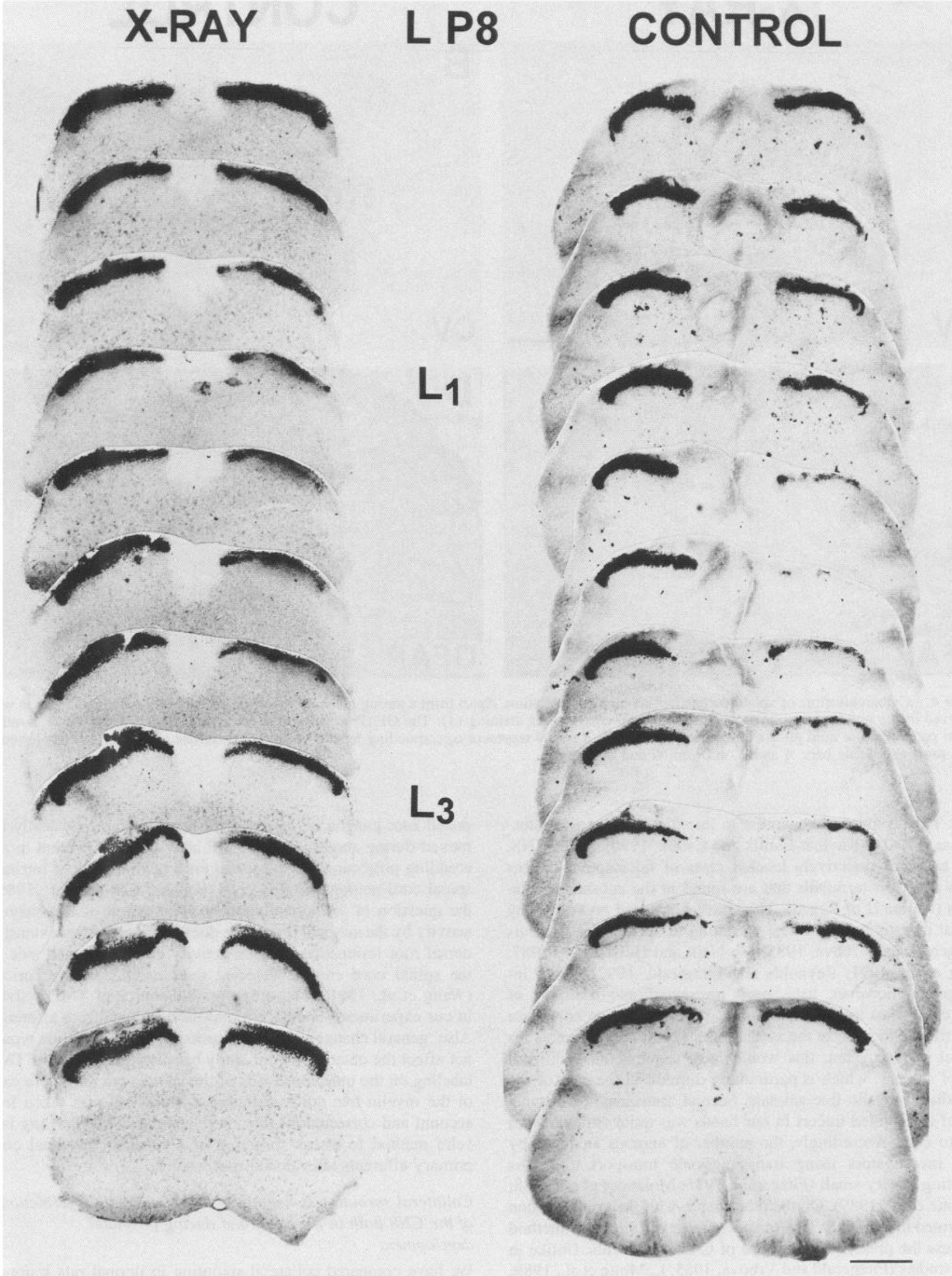


ents showed that the volume devoid of TMP-positive fibers in rats deafferented at P8 was less than in animals lesioned at later time points. The difference in TMP-labeled volume was small between rats lesioned at P8 and P15, but was more pronounced between rats lesioned at P8 or P15 and rats lesioned as young adults (P28). This time dependency for sprouting is temporally correlated with the developmental downregulation of the growth-associated protein GAP-43 in the spinal cord and the increase in myelin formation during development (Kapfhammer and Schwah, 1994a). Different CNS regions hecome myelinated at different time points and to different degrees (Schwab and Schnell, 1989). In the substantia gelatinosa, myelin formation starts rather late (at about P16) and reaches only low degrees in the adult (Kapfhammer and Schwab, 1994a). In animals lesioned at P8, sprouting can occur during the first week of survival in an environment virtually free of myelin. After this first week, an increasing amount of myelin can be expected to be present and the associated neurite growth inhibitors might interfere with sprouting. In animals lesioned at P15, weak myelination will be present already at the beginning of the survival period, and in animals lesioned at P28 myelination will be almost adult-like at the time of the lesion. It can therefore be expected that sprouting gradually declines in animals lesioned between P8 and P28. Our results are well in agrecment with this prediction. Thereforc, the enhanced sprouting in early postnatal rats can be correlated with the absence of myelin and the associated neurite growth inhibitors in the microenvironment of the sprouting fibers.

In adult animals, collateral sprouting in the CNS is scarce and has most often been reported to occur in lightly myelinated areas such as the olfactory system (Devor, 1976), the hippocampus (Cotman et al., 1981), the septum (Raisman and Field, 1973), the molecular layer of the cerebellum (Rossi et al., 1991), and the substantia gelatinosa (Molander et al., 1988; LaMotte et al., 1989). During development, collateral sprouting is markedly increased in the spinal cord (Hulsebosch and Coggeshall, 1983a,b; Fitzgerald, 1985). Furthermore, at early developmental stages, collateral sprouting is reported to take place in CNS regions that fail to sprout in the adult. For example, in the postnatal principal trigeminal nucleus, lesion-induced plastic changes are restricted to an altered dendritic arborization without detectable collateral sprouting (Renehan et al., 1989, 1994). In this region, sprouting can only be found after lesions at fetal stages (Rhoades et al., 1989). A similar situation exists for lesion-induced sprouting of corticospinal tract fibers within spinal cord gray matter. These fibers become severely restricted in their ability to sprout between P19 and P23 (Kuang and Kalil, 1990). Both of these regions are densely myelinated in the adult. Because of these findings and our own observations, we believe that the growthpermissive environment present during embryonic development and at young postnatal stages becomes nonpermissive or inhibitory at the onset of myelination (Kapfhammer and Schwab, 1994a). Interestingly, the beginning of myelination is well correlated with the end of "critical periods" for anatomical plasticity in the CNS during postnatal development. In the visual system of newborn rats, ferrets, and monkeys, for example, the thalamic afferents expand their territory in the visual cortex rap- idly after occlusion of one eye (Kaas et al., 1983; Antonini and Stryker, 1993). This anatomical plasticity ends at a given postnatal age ( $8-10$ weeks in the cat) and is not seen in adult animals. In the cat, the end of this critical period is closely correlated with the onset of myelination and the appearance of myelin-associated neurite growth inhibitors in the visual cortex (Muiller et al., 1993). Myelination and the concomitant inhibition of fiber growth and sprouting might therefore be an important mechanism for the stabilization of neuronal connections after completion of developmental processes.

\section{Effects of neonatal $x$-irradiation on the developing spinal cord}

Neonatal $x$-irradiation can be applied locally to particular CNS regions, which results in virtually complete suppression of myelin formation (Gilmore, 1963a,b; Savio and Schwab, 1990). At P0, oligodendrocyte precursor cells are strongly proliferating, whereas many astrocytes and most neurons have already reached a postmitotic state (Gilmore, 1971; Altman and Bayer, 1984). In vitro studies have shown that oligodendrocyte precursors are extremely sensitive to $x$-irradiation (Hirayama et al., 1984). Four weeks after $x$-irradiation, only few fibers in the ventral funiculi are myelinated most probably by oligodendrocyte precursors as opposed to migrating Schwann cells (Kapfhammer and Schwab, 1994b). Ncuritc growth inhibitory molccules could not be detected by immunostaining with the antibody IN-1 throughout the gray and white matter (even 5 weeks after $x$-irradiation). In contrast, the cytoarchitecture of the $x$-irradiated spinal cords appeared remarkably unaffected as judged by cresyl violet staining. The different laminae of the gray matter remained well defined and the neurons seemed well differentiated. GFAP immunhistochemistry revealed an almost nomal distribution paltern of astrocytes. The only detectable abnormalities included a mild gliosis in the gray matter and an increased density of GFAPlabeled processes in the shrunken white matter. Thus, the most striking effect of neonatal $\mathrm{x}$-irradiation is the suppression of oligodendrocyte differentiation and myelination. Although unspecific effects of the $\mathrm{x}$-ray treatment on neurons and astrocytes cannot be ruled out completely, the most likely reason for the differences found in sprouting between normal and $\mathrm{x}$-irradiated spinal cords is the absence of myelin and the associated neurite growth inhibitors.

Remarkably, we have observed that TMP-labeled fibers did occupy a wider area in the upper dorsal horn of $\mathrm{x}$-irradiated spinal cords when compared to control animals. Part of this increase of the TMP-positive area may be due to a reduced retraction of TMP-positive terminals from the lower part of lamina II as observed during normal development (Coimbra et al., 1986). In addition, the enlarged TMP-positive area may also reflect a partial extension of TMP-positive afferents into lamina III. These findings are consistent with the observations of Schwab and Schnell (1991), who found an abnormal development of the corticospinal tract (CST) in x-irradiated, myelin-free spinal cords as well as in animals in which myelin-associated neurite growth inhibitors were neutralized by application of the monoclonal antibody IN-1. In both experimental conditions, the cross section of the CST was enlarged and sprouting of CST

$\leftarrow$

Figure 5. Sprouting of TMP-positive afferents in myelin-free spinal cord after lesion at P8: comparison of the extent of collateral sprouting in serial sections of lumbar spinal cords lesioned at P8 (myelin-free, left column; normal, right column). In the myelin-free spinal cord, there is a better filling of the deafferented area by TMP-positive fibers as compared to the control spinal cord. The entrance of dorsal roots L1 and L3 is indicated. Scale bar, $400 \mu \mathrm{m}$. 


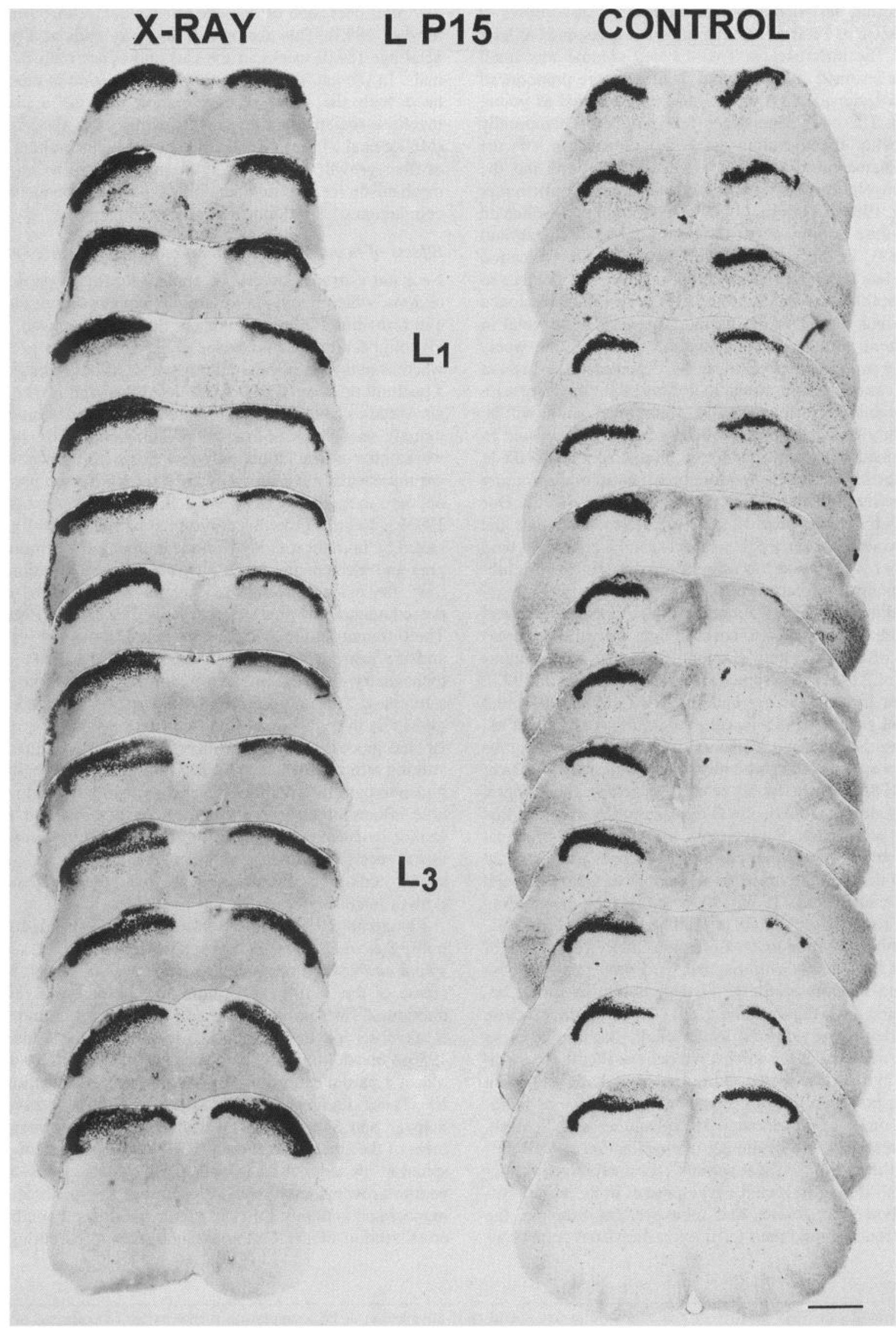

Figure 6. Sprouting of TMP-positive afferents in myelin-free spinal cord after lesion at P15: comparison of the extent of collateral sprouting in serial sections of lumbar spinal cords lesioned at P15 (myelin-free, left column; normal, right column). In the myelin-free spinal cord there is a 
fibers into the surrounding gray matter increased. Schwab and Schnell have proposed that myelin and myelin-associated neurite growth inhibitors may serve as an inhibitory boundary for lategrowing fiber tracts in the CNS. In the developing spinal cord, the layering of afferent fibers in the gray matter occurs prior to myelination. The adult-like somatotopic order of primary afferents in the substantia gelatinosa is already established at P2 (Fitzgerald and Swett, 1983). Similarly, the laminar organization develops early during development (Smith, 1983; Coimbra et al., 1986; Shortland and Fitzgerald, 1994). Our findings, therefore, might indicate that the myelination of lamina III prevents layer II afferents from sprouting into lamina III at later stages. Interestingly, afferents from layer III are known to be able to sprout into the lightly myelinated layer II of normal adult spinal cords after peripheral nerve lesions (Woolf et al., 1992). Myelination and the associated neurite growth inhibitors, therefore, might be involved in the stabilization of the layering of primary afferents in spinal cord gray matter.

\section{Increased collateral sprouting in the myelin-free spinal cord}

As discussed above, there is evidence that myelination and sprouting are negatively correlated in the CNS. In the present study, we have tested whether collateral sprouting could be enhanced by experimentally suppressing myelin formation in the spinal cord. Our results show that lesion-induced sprouting is strongly enhanced in a myelin-free environment. Although the substantia gelatinosa normally contains little myelin, this is obviously sufficient to markedly limit collateral sprouting. In the myelin-free environment, sprouting is robust and very similar after lesions both at P8 and P15 (in contrast to normally myelinated animals). These findings suggest that in the upper dorsal horn the extent of sprouting is restricted by the local environment. However, it should be noted that myelination is not the only factor that determines the amount of collateral sprouting of spinal cord afferents. It has been shown that the intrinsic capacity of sensory fibers to sprout can be enhanced by crushing of the peripheral nerve (Molander et al., 1988; McMahon and KettWhite, 1991). Even crushing of the peripheral nerve alone (without deafferentation) results in sprouting of spinal cord primary afferents (Florence et al., 1993). C-fibers have been shown to depend on NGF as a neurotrophic factor during development (Ruit et al., 1992). The stimulating effect of nerve crush might therefore be related to an increased supply of neurotrophic factors to dorsal root ganglion neurons. In addition, neurotrophic factors have been shown to enhance sprouting of lesioned CST fibers (Schnell et al., 1994). In this study, we have not attempted to further stimulate sprouting of TMP-positive afferents by supplying NGF or by crushing peripheral nerves in animals with myelin-free spinal cords. Whether the amount of sprouting found in this study can be further enhanced by such a treatment remains to be determined.

Until now, very few data are available about collateral sprouting in those CNS regions in which myelination was suppressed or in which myelin-associated neurite growth inhibitors were neutralized by antibodies. It has been shown that in $\mathrm{x}$-irradiated, myelin-free optic nerves, the total fiber number was $10-30 \%$ higher than in myelinated control nerves. In addition, fiber num-

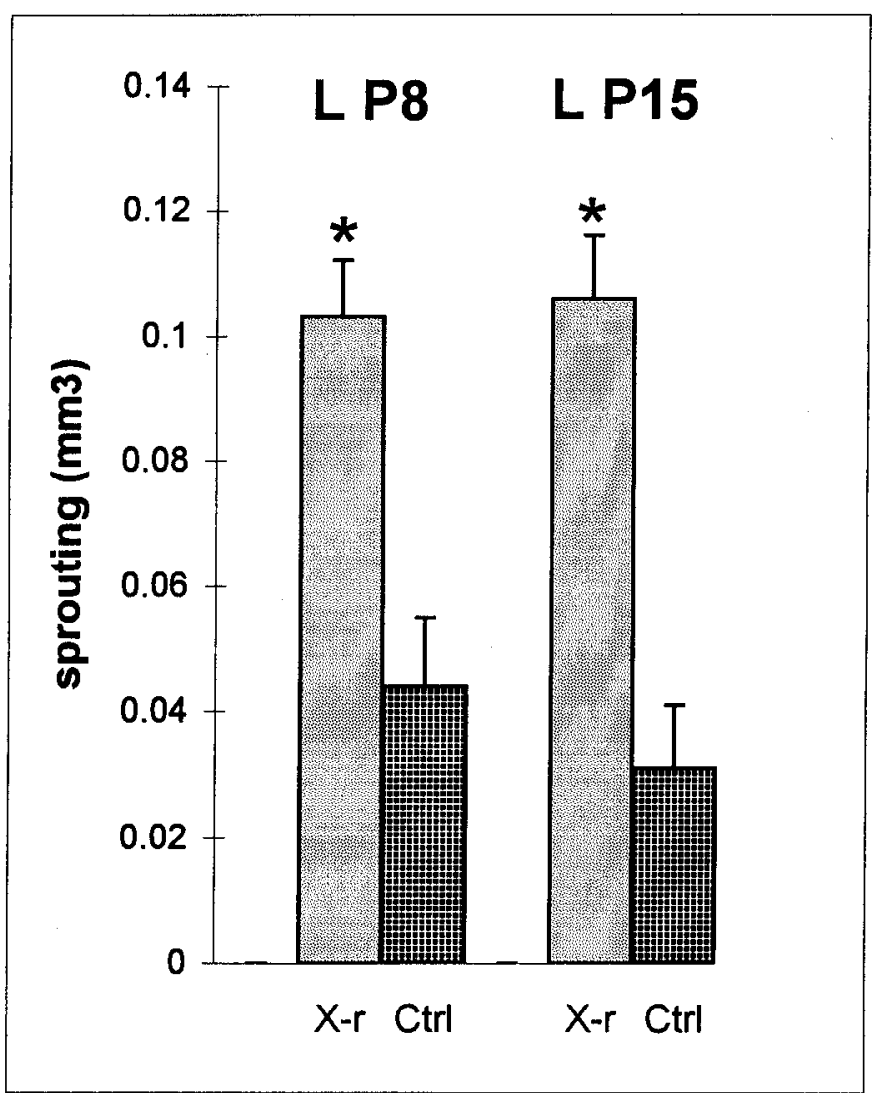

Figure 7. Increased sprouting in the myelin-free spinal cord; sprouting values of primary afferent fibers in myelin-free spinal cords $(X-r)$ compared to age-matched controls $(C t r l)$. Values are shown as the means \pm SEM. In myelin-free spinal cords, collateral sprouting is increased after lesions at P8 $(L P 8)$ or P15 ( $L P 15)$ as compared to the control groups. Asterisks indicate significance of $p<0.001$.

bers fluctuated along the length of the myelin-free nerve (Colello and Schwab, 1994), suggesting a formation of collaterals in the myelin-free nerves. Another example for sprouting of primary afferents in an experimentally manipulated environment was described by Kapfhammer et al. (1992). After early postnatal unilateral ablation of the superior colliculus together with the ipsilateral eye in hamsters, the contralateral undamaged retinotectal fibers cross the midline to innervate the remaining deafferented colliculus. These fibers only terminate in the superficial gray layer (which is almost unmyelinated), but not in the myelinated deeper optic fiber layer (stratum opticum) of the colliculus. Application of the IN-1 antibody (which neutralizes myelin-associated neurite growth inhibitors) allowed the sprouting fibers to penetrate into and terminate in the myelinated stratum opticum. In both of these experiments, myelination and the associated neurite growth inhibitors were shown to inhibit or restrict sprouting in the CNS in a manner similar to that observed in the present study.

\section{Neurite growth inhibitors as regulators of anatomical} plasticity

It has been proposed that in the normal CNS, nerve fibers and axon terminals compete continuously with each other for post- 
synaptic space (Hubel and Wicscl, 1965; Purves and Lichtman, 1983; Chiaia et al., 1994). Neural connections attain a stable state when this competition reaches an equilibrium. However, when the balance between the competing terminals is disturbed (e.g., by altered functional activity), the terminals can react by sprouting and retraction until a new equilibrium is reached. A partial deafferentation, as carried out in our experiments, might therefore be considered an extreme example of such an imbalance. The degeneration of the lesioned fibers would allow the intact neighbouring terminals to partially take over the vacated postsynaptic space. Alternatively, one could disturb the equilibrium by strengthening a population of axons through application of neurotrophic factors or by crushing their peripheral processes. In the upper dorsal horn, crush of peripheral afferent nerve processes alone has been shown to elicit sprouting (Florence et al., 1993). These rather crude attempts to induce imbalance in the CNS are likely to reflect more subtle changes that are continuously occurring within the normal CNS. Morphological changes, for example, have been observed after learning paradigms (Cavazos et al., 1991; Geinisman et al., 1992; Doubell and Stewart, 1993). Furthermore, changes in synaptic densities and synaptic morphology have been found in animals exposed to different environments (Vrensen and Nunes Cardozo, 1981; Green et al., 1983; Patel et al., 1988).

While it is clear that collateral sprouting can contribute to the functional recovery seen after CNS lesions, changes in neuronal connectivity after lesions or changes resulting from altered functional activity may not always be beneficial for the organism. For example, the regrowth of optic fibers after a unilateral lesion of the superior colliculus can induce inappropriate behavioral responses in hamsters (Schneider, 1979). Similarly, sprouting of low-threshold mechanoreceptor afferents into the target area of nociceptive fibers might act as a morphological substrate for neuralgic pain after peripheral nerve lesions in humans (Woolf et al., 1992). As shown in this study, the loss of oligodendrocytes and myelin leads to a strong enhancement of C-fiber sprouting after a partial spinal cord deafferentation. Myelin and the associated neurite growth inhibitors, therefore, may have a role in limiting plastic changes after the completion of developmental processes. Importantly, this restriction of plastic changes would be spatially regulated within the mature CNS. Regions that are lightly myelinated would be more permissive for plastic changes than densely myelinated regions. Precise point-to-point connections, such as the mechanoreceptor afferents from the skin and muscle or the retinothalamic projection, require a high stability in order to avoid inappropriate behavior of the organism. These precise projections are strongly myelinated in the adult and express only small amounts of the growth associated protein GAP-43 (Kapfhammer and Schwab, 1994a). More diffuse projections, such as the nociceptive C-fibers or the autonomic afferents terminating in the nucleus of the solitary tract, are only lightly myelinated and maintain high GAP-43 levels. We therefore suggest that myelin and its associated neurite growth inhibitors play an important role in regulating the stability of neuronal connections. They might, in this way, determine the extent to which plastic changes are possible in different regions of the normal adult CNS.

\section{References}

Altman J, Bayer SA (1984) The development of the rat spinal cord. Adv Anat Embryol Cell Biol 85:1-166.
Antonini A, Stryker MP (1993) Rapid remodeling of axonal arbors in the visual cortex. Science 260:1819-1821.

Bandtlow C, Zachleder T, Schwab ME (1990) Oligodendrocytes arrest ncuritc growth by contact inhibition. J Neurosci 10:3837-3848.

Benowitz LI, Perrone-Bizzozero NI (1991) The expression of GAP-43 in relation to neuronal growth and plasticity: when, where how, and why? Prog Brain Res 89:69-87.

Caroni P, Schwab ME (1988a) Two membrane protein fractions from rat central myelin with inhibitory properties for neurite growth and fiberglass spreading. J Cell Biol 106:1281-1288.

Caroni P, Schwab ME (1988b) Antibody against myelin-associated inhibitor of neurite growth neutralizes nonpermissive substrate properties of CNS white matter. Neuron 1:85-96.

Caroni P, Schwab ME (1989) Codistribution of neurite growth inhibitors and oligodendrocytes in rat CNS: appearance follows nerve fiber growth and precedes myelination. Dev Biol 136:287-295.

Cavazos JE, Golarai G, Sutula TP (1991) Mossy fiber synaptic reorganization induced by kindling: lime course of development, progression, and permanence. J Neurosci 11:2795-2803.

Chiaia NL, Zhang S, King TD, Rhoades RW (1994) Evidence for prenatal competition among the central arbors of trigeminal primary afferent neurons: single axon analysis. J Comp Neurol 345:303-313.

Coimbra A, Ribeiro-Da-Silva A, Pignatelli D (1986) Rexed's laminae and the acid phosphatase (FRAP)-band in the superficial dorsal horn of the neonatal rat spinal cord. Neurosci Lett 71:131-136.

Colello RJ, Schwab ME (1994) A role for oligodendrocytes in the stabilization of optic axon numbers. J Neurosci, 14:6446-6452.

Cotman CW, Nietro-Sampedro M, Harris EW (1981) Synapse replacement in the nervous system of adult vertebrates. Physiol Rev 61:684784.

Devor M (1976) Neuroplasticity in the rearrangement of olfactory tract fibers after neonatal transections in hamsters. J Comp Neurol 166: $49-72$.

Doubell TB, Stewart MG (1993) Short-term changes in the numerical density of synapses in the intermediate and medial hyperstriatum ventrale following one-trial passive avoidance training in the chick. $J$ Nenrosci 13:2230-2236.

Fitzgerald M (1985) The sprouting of saphenous nerve terminals in the spinal cord following early postnatal sciatic nerve section in the rat. J Comp Neurol 240:407-413.

Fitzgerald M, Swett J (1983) The termination pattern of sciatic nerve afferents in the substantia gelatinosa of neonatal rats. Neurosci Let 43:149-154.

Fitzgerald M, Vrbova G (1985) Plasticity of acid phosphatase (FRAP) afferent terminal fields and of dorsal horn cell growth in the neonatal rat. J Comp Neurol 240:414-422.

Florence SL, Garraghty PE, Carlson M, Kaas JH (1993) Sprouting of peripheral nerve axons in the spinal cord of monkeys. Brain Res 601: 343-348.

Geinisman Y, Morrell F, de Toledo-Morrell L (1992) Increase in the number of axospinous synapses with segmented postsynaptic densities following hippocampal kindling. Brain Res 569:341-347.

Gilmore SA (1963a) The effects of $x$-irradiation on the spinal cords of neonatal rats. I. Neurological observations. J Neuropathol Exp Neurol 22:285-293.

Gilmore SA (1963b) The effects of $x$-irradiation on the spinal cords of neonatal rats. II. Histological observations. J Neuropathol Exp Neurol 22:294-301.

Gilmore SA (1971) Neuroglial population in the spinal cord white matter of neonatal and early postnatal rats: an autoradiographic study of numbers of neuroglia and changes in their proliferative activity. Anat Rec 171:283-292.

Green EJ, Greenough WT, Schlumpf BE (1983) Effects of complex environments on cortical dendrites of middle-aged rats. Brain Res 264:233-240.

Hirayama M, Eccleston PA, Silberberg DH (1984) The mitotic history and radiosensitivity of developing oligodendrocytes in vitro. Dev Biol 104:413-420.

Hubel DH, Wiesel TN (1965) Binocular interaction in striate cortex of kittens reared with artificial squints. J Neurophysiol 23:1041-1059.

Hulsebosch CE, Coggeshall RE (1983a) A comparison of axonal numbers in dorsal roots following hemisection in neonate and adult rats. Brain Res 265:187-197.

Hulsebosch CE, Coggeshall RE (1983b) Age related sprouting of dorsal root axons after sensory denervation. Brain Res 288:77-83. 
Kaas JH, Merzenich MM, Killackey HP (1983) The reorganization of somatosensory cortex following peripheral nerve damage in adult and developing mammals. Annu Rev Neurosci 6:325-356.

Kapfhammer JP, Schwab ME (1994a) Inverse patterns of myelination and GAP-43 expression in the adult CNS: neurite growth inhibitors as regulators of neuronal plasticity? J Comp Neurol 340:194-206.

Kapfhammer JP, Schwab ME (1994b) Increased expression of growthassociated protein GAP-43 in the myelin-free rat spinal cord. Eur J Neurosci 6:403-411.

Kapfhammer JP, Schneider GE, Schwab ME (1992) Antibody neutralization of neurite growth inhibitors from oligodendrocytes results in expanded pattern of postnatally sprouting retinocollicular axons. J Neurosci 12:2112-2119.

Knyihar E, Csillik B (1976) Effect of peripheral axotomy on the fine structure and histochemistry of the Rolando substance. Expl Brain Res 26:73-87.

Knyihar-Csillik E, Csillik B (1990) Structural, functional and cytochemical plasticity of primary afferent terminals in the upper dorsal horn. In: The primary afferent neuron. A survey of recent morphofunctional aspects (Zenker W, Neuhuber WL, eds), pp 227-251. New York: Plenum

Knyihar-Csillik E, Bezzegh A, Boti S, Csillik B (1986) Thiamine monophosphatase: a genuine marker for transganglionic regulation of primary sensory neurons. J Histochem Cytochem 34:363-371.

Kuang RZ, Kalil K (1990) Specificity of corticospinal axon arbors sprouting into denervated contralateral spinal cord. J Comp Neurol 302:461-472.

LaMotte CC, Kapadia SE, Kocol CM (1989) Deafferentation-induced expansion of saphenous terminal field labelling in the adult rat dorsal horn following pronase injection of the sciatic nerve. J Comp Neurol 288:311-325.

McMahon SB, Kett-White R (1991) Sprouting of peripherally regenerating primary sensory neurons in the adult central nervous system. J Comp Neurol 304:307-315.

Mc Neill DL, Hulsebosch CE (1987) Intraspinal sprouting of rat primary afferents after deafferentation. Neurosci Lett 81:57-62.

Molander C, Kinnman E, Aldskogius H (1988) Expansion of spinal cord primary sensory afferent projection following combined sciatic nerve resection and saphenous nerve crush: a horseradish peroxidase study in the adult rat. J Comp Neurol 276:436-441.

Müller CM, Rubin B, Schwab ME (1993) Critical-period dependent expression of the myelin-associated neurite growth inhibitor NI35/250 in cat visual cortex. Soc Neurosci Abstr 19:240.

Patel SN, Rose SPR, Stewart MG (1988) Training induced dendritic spine density changes are specifically related to memory formation processes in the chick, Gallus domesticus. Brain Res 463:168-173.

Phifer CB, Terry LM (1986) Use of hypothermia for general anaesthesia in preweanling rodents. Physiol Behav 38:887-890.

Pubols LM, Bowen DC (1988) Lack of central sprouting of primary afferent fibers after ricin deafferentation. J Comp Neurol 275:282287.

Purves D, Lichtman JW (1983) Specific connections between nerve cells. Annu Rev Physiol 45:553-565.

Raisman G, Ficld PM (1973) A quantitative investigation of the development of collateral reinnervation after partial deafferentation of the septal nuclei. Brain Res 50:251-264.

Renehan WE, Rhoades RW, Jacquin MF (1989) Structure-function relationship in rat brainstem subnucleus interpolaris: VII. Primary afferent central terminal arbors in adults subjected to infraorbital nerve section at birth. J Comp Neurol 289:493-508.

Renehan WE, Crissman RS, Jacquin MF (1994) Primary afferent plasticity following partial denervation of the trigeminal brainstem nuclear complex in the postnatal rat. J Neurosci 14:721-739.
Reynolds ML, Fitzgerald M (1992) Neonatal sciatic nerve section results in thiamine monophosphatase but not substance $\mathrm{P}$ or calcitonin gene-related peptide depletion from the terminal field in the dorsal horn of the rat: the role of collateral sprouting. Neuroscience 1:199202.

Rhoades RW, Chiaia NL, MacDonald GJ, Jacquin MF (1989) Effect of fetal infraorbital nerve transection upon trigeminal primary afferent projections in the rat. J Comp Neurol 287:82-97.

Rossi F, Wiklund L, van der Want JJL, Strata P (1991) Reinnervation of cerebellar Purkinje cells by climbing fibers surviving a subtotal lesion of the inferior olive in the adult rat. I. Development of new collateral branches and terminal plexuses. J Comp Neurol 308:513535.

Rubin BP, Dusart I, Schwab ME (1994) A monoclonal antibody (IN1) which neutralizes neurite growth inhibitory proteins in the rat CNS recognizes antigens localized in CNS myelin. J Neurocytol 23:209217.

Ruit KG, Elliott JL, Osborne PA, Yan Q, Snider WD (1992) Selective dependence of mammalian dorsal root ganglion neurons on nerve growth factor during embryonic development. Neuron 8:573-587.

Savio T, Schwab ME (1990) Lesioned corticospinal tract axons regenerate in myelin-free rat spinal cord. Proc Natl Acad Sci USA 87: $4130-4133$

Schneider GE (1973) Early lesions of the superior colliculus: factors affecting the formation of abnormal projections. Brain Behav Evol 8:73-109.

Schneider GE (1979) Is it really better to have your brain lesion early? A revision of the "Kennard principle." Neuropsychologia 17:557583.

Schnell L, Schwab ME (1990) Axonal regeneration in the rat spinal cord produced by an antibody against myelin-associated neurite growth inhibitors. Nature 343:269-272.

Schnell L, Schwab ME (1993) Sprouting and regeneration of lesioned corticospinal tract fibers in the adult rat spinal cord. Eur $\mathbf{J}$ Neurosci 5:1156-1171.

Schnell L, Schneider R, Kolbeck R, Barde Y-A, Schwab ME (1994) Neurotrophin-3 enhances sprouting of corticospinal tract during development and after adult spinal cord lesion. Nature 367:170-173.

Schwab ME, Schnell L (1989) Region-specific appearance of myelin constituents in the developing rat spinal cord. J Neurocytol 18:161169.

Schwab ME, Schnell L (1991) Channeling of developing rat corticospinal tract axons by myelin-associated neurite growth inhibitors. J Neurosci 11:709-721.

Shortland P, Fitzgerald M (1994) Neonatal sciatic nerve section results in a rearrangement of the central terminals of saphenous and axotomized sciatic nerve afferents in the dorsal horn of the spinal cord of the adult rat. Eur J Neurosci 6:75-86.

Skene JHP (1989) Axonal growth-associated proteins. Annu Rev Neurosci $12: 127-156$.

Smith CL (1983) The development and postnatal organization of primary afferent projections to the rat thoracic spinal cord. J Comp Neurol 220:29-43.

Strittmatter SM, Vartanian T, Fishman M (1992) GAP-43 as a plasticity protein in neuronal form and repair. J Neurobiol 23:507-520.

Vrensen G, Nunes Cardozo J (1981) Changes in size and shape of synaptic connections after visual training: an ultrastructural approach of synaptic plasticity. Brain Res 218:79-97.

Wang SD, Goldberger ME, Murray M (1991) Normal development and the effects of early rhizotomy on spinal systems in the rat. Dev Brain Res 64:57-69.

Woolf CJ, Shortland P, Coggeshall RE (1992) Peripheral nerve injury triggers central sprouting of myelinated afferents. Nature 355:75-78. 